\title{
Characterization of Magnaporthe oryzae triticum on Different Culture Media
}

\author{
M. L. Ashrafi ${ }^{1}$, F. M. Aminuzzaman ${ }^{1 *}$ (D), M. K. Rehena ${ }^{1}$, J. F. Tanni ${ }^{1}$, M. Ahmed ${ }^{2}$ \\ ${ }^{1}$ Department of Plant Pathology, Faculty of Agriculture, Sher-e-Bangla Agricultural University, Sher-e-Bangla Nagar, Dhaka, \\ Bangladesh \\ ${ }^{2}$ Scientific Officer, Plant Pathology Division, Bangladesh Rice Research Institute, Gazipur, Bangladesh \\ Email: *aminsaupp@yahoo.com
}

How to cite this paper: Ashrafi, M.L., Aminuzzaman, F.M., Rehena, M.K., Tanni, J.F. and Ahmed, M. (2021) Characterization of Magnaporthe oryzae triticum on Different Culture Media. Open Access Library Journal, 8: e7521.

https://doi.org/10.4236/oalib.1107521

Received: May 13, 2021

Accepted: December 5, 2021

Published: December 8, 2021

Copyright () 2021 by author(s) and Open Access Library Inc.

This work is licensed under the Creative Commons Attribution International License (CC BY 4.0).

http://creativecommons.org/licenses/by/4.0/

\begin{abstract}
Wheat blast caused by the fungus Magnaporthe oryzae triticum (MoT) is one of the most devastating diseases of wheat. It has caused crop losses up to $40 \%$ to $100 \%$ in various wheat cultivars in different wheat growing regions. Understanding pathogenic variation, cultural and morphological characterization of MoT isolates is one of the most efficient ways to manage the disease. This study was carried out for isolation and pathogenicity of MoT isolates and evaluation of three culture media namely Oat Meal Agar (OMA), Potato Dextrose Agar (PDA) and Potato Sucrose Agar (PSA) for their growth and cultural characteristics. Wheat blast sample was collected from different fields in two districts during the Rabi cropping season in February to March 2019, in major wheat growing areas viz. Meherpur, Mujibnagar and Chuadanga sadar upazila. A total of $15 \mathrm{MoT}$ isolates were identified and characterized based on their growth parameters. MoT isolates showed comparatively higher mean mycelial growth rate on OMA ( $15.43 \mathrm{~mm}$ per day) media followed by PDA (14.34 mm per day) at 4 DAI. Minimum mean mycelial growth rate was recorded on PSA (14.02 $\mathrm{mm}$ per day).
\end{abstract}

Subject Areas
Agricultural Science

Keywords

Wheat Blast, Culture Media, Magnaporthe oryzae triticum

\section{Introduction}

Wheat (Triticum aestivum) is one of the world's most important grains and a 
leading source of calories and plant protein in human foods [1]. Wheat is synonymous with food for a large part of the global food security and population of developing countries. Wheat originated from the nearby Levant region of the east but is now cultivated worldwide. It grows in more than 70 countries on 5 continents [2] and is the most widely grown crop in the world. In 2017, world production of wheat was 771.7 million tonnes, making it the third most produced cereal [3]. Wheat is grown on more than 1.5 million hectares, which is larger than any other crop.

Wheat blast caused by Pyricularia oryzae pathotype triticum (PoT) reported as a devastating disease of wheat [4]. Wheat blast, or 'brusone', is caused by the haploid, filamentous, ascomycetous fungus Magnaporthe oryzae (synonym to Pyricularia oryzae Cavara 1892) [5]. This devastating disease can cause damage from $40 \%$ [6] to $100 \%$ [7] [8] under the favourable environmental conditions. Wheat blast caused by Magnaporthe oryzae triticum (MoT) is basically a head disorder. Common symptoms have also been described from small elliptical lesions to complete bleaching and empty spikes [9]. Additionally, in some fields, blackening of lower nodes was observed. Grains from blast-infected heads were small, shriveled, deformed, and had low test-weight leading to serious yield losses [10].

After its origin in Parana, the pathogen followed the agricultural expansion to the warm Cerrado areas of central-western Brazil, arriving in Minas Gerais in 1990 [11] [12], and Brasilia in 1993 [13], spreading about $1200 \mathrm{~km}$ north from its origin. It also spread to cooler regions $1200 \mathrm{~km}$ south-west of Parana, reaching Chaco and Corrientes provinces in Argentina in 2007 [14]. The economic importance of this disease derives from the fact that the fungus can reduce yield and the quality of the wheat grain. Infected grains from highly susceptible cultivars are usually small, wrinkled, deformed, and have low-test weight. The highest yield losses occur when infections start during flowering or grain formation [15].

In February 2016, Bangladesh was identified as the first Asian country to have the origin of the alarming wheat blast disease caused by a South American lineage of a hemibiotrophic filamentous fungus Magnaporthe oryzae triticum (MoT) pathotype [16]. With the first emergence of Bangladesh, wheat blast has entered Asia, which accounts for about $42 \%$ of the world's wheat production. Thought the first occurrence of wheat blast during 2015-16 cropping season was restricted to eight districts of Bangladesh the outbreak spread to more neighboring districts namely Magura, Faridpur and Rajshahi in 2016-17, 2017-18 cropping season. According to the data of the Bangladesh Department of Agriculture Extension total area of wheat cultivation in the blast affected districts during the year 2015-16 and 2016-17 was 99,259 and 47,278 hectares, respectively.

Since this wheat killer is in progress, the need for rapid development of effective management methods, including the development of blast-resistant varieties 
using modern biotechnological approaches, including genome editing is essential before it becomes catastrophizing (Islam, et al., 2019) [17]. Field study as well as in vitro study of the growth and sporulation of MoT isolates is important to formulate control strategy. Castruagudin et al. (2016) [18] used four culture media such as corn meal agar (CMA), malt-extract agar (MEA), Oat meal agar (OMA) and Potato dextrose agar (PDA) for studying the growth of PoT. They found maximum growth of PoT on PDA media though the growth study was not determined to evaluate different isolates from a geographic origin. In this study we isolated and identified $15 \mathrm{MoT}$ isolates and used three culture media to study their mycelial growth and other morphological characteristics of the colony. Keeping this review in mind the present research work was conducted to isolate, identify and pathogenicity study of wheat blast pathogen Magnaporthe oryzae triticum (MoT) and to determine the morphological and cultural diversity of different isolates of MoT in different culture media in-vitro.

\section{Materials and Methods}

The present research work was carried out both in field and laboratory condition to determine variation of different isolates on different growth media during January 2018 to April 2019. The details of the materials and methodology adopted during this study are described here under the following points.

\subsection{Survey and Experimental Sites}

The survey was made in the farmer's wheat fields which were affected by wheat blast disease at Meherpur and Mujibnagar upazila in Meherpur district and Chuadanga sadar upazila in Chuadanga district in Bangladesh in January to April, 2018 and 2019. The laboratory experiment was conducted from February 2018 to April 2019 in the Plant Pathology Laboratory, Sher-e-Bangla Agricultural University, Sher-e-Bangla Nagar, Dhaka-1207.

\subsection{Sampling}

Sampling was carried out in different areas of Meherpur, Mujibnagar and Chuadanga Sadar upazila by taking wheat blast infected panicles. Five random spots $(1 \mathrm{~m} \times 1 \mathrm{~m})$ were selected for each field. At least 3 samples were collected from each spot. Samples were kept into brown paper envelopes. After sample collection, all required information were labeled on brown paper envelopes, such as a field site, farmer's name, variety, date of collection etc. Samples were kept in a refrigerator for 3 hours at $4^{\circ} \mathrm{C}$. When all the preparations were done for isolation, the samples were taken out of the refrigerator and transferred to the Plant Pathology Laboratory of Sher-e-Bangla Agricultural University for isolation, identification, and characterization.

\subsection{Isolation and Identification of MoT Isolates}

Infected rachis was used for isolation of MoT isolates. At first glumes were re- 
moved from rachis and whole rachis was cut into small pieces $(12-15 \mathrm{~cm})$. Then they were surface sterilized by using $1 \%$ sodium hypochlorite for $1 \mathrm{~min}$ following by rinsing with distilled water at least 3 times. After sterilization they were placed into previously sterilized petridishes having what man filter paper. Small amount of distilled water was sprayed over the sample and lid was closed. Then the petridishes were incubated at $25^{\circ} \mathrm{C}$ for 24 hours. Water agar and PDA (Potato dextrose agar) were used for isolation of MoT. After incubation, infected rachis was examined under stereo dissecting microscope for observation of pathogenic growth and sporulation around the infected lesion having blackish, bushy appearance. A sterilized pin pointed needle was used to pick up conidia from the sporulated portion and put into water agar (WA) and incubated petri dishes at $25^{\circ} \mathrm{C}$ for 2 days for growth and development of mycelia. After 2 days' mycelia tip was separated and recultured to PDA containing oramycin-B (antibacterial) by hyphal tip culture technique. Petri dishes containing PDA were incubated at $25^{\circ} \mathrm{C}$ for 3 - 4 days with alternating 12 hours light and 12 hours darkness. Cultural and Morphological study was done following Castroagudin et al. (2016) [18]. Slides were made from the culture and observed under light microscope on the basis of conidia or spore for identifying MoT (Figure 1).

\subsection{Designation of MoT isolates}

MoT isolates were designated following Aminuzzaman et al. 2010 with little modification [19]. For example an isolate designated by MEMoT13 represents that this isolate was collected from district Meherpur (ME), MoT represents Magnaporthe oryzae triticum and 13 denotes collection number.

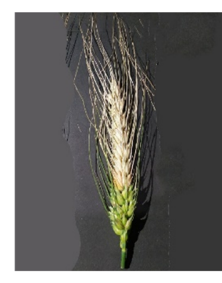

(a) Bleached panicle

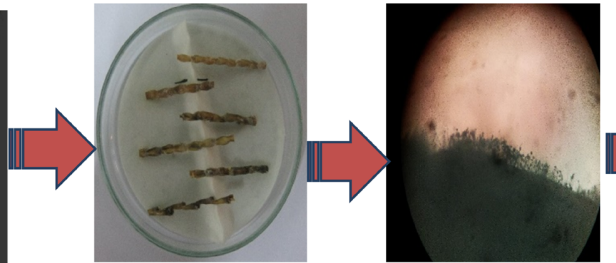

(b) Moist Chamber (c) Under Stereomicroscope

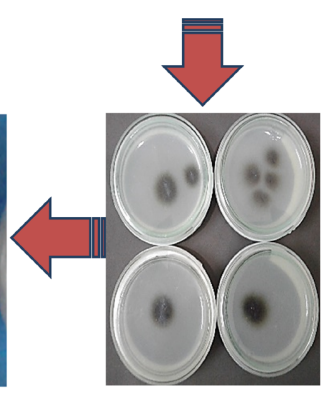

(f) Pure culture on PDA (e) Mycelial growth on

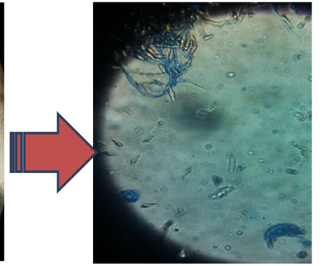

(d) Under Compound Microscope

(g) Single conidium

Figure 1. Flow chart of isolation and identification of wheat blast pathogen MoT. (a) infected wheat panicle; (b) infected rachis incubated into moist chamber; (c) sporulation of MoT under stereomicroscope (40x); (d) conidia of MoT under compound microscope (40x); (e) mycelial growth of MoT on water agar; (f) Pure culture of MoT on PDA and (g) single MoT conidium under compound microscope $(60 \times)$. 


\subsection{Maintenance of Isolates of MoT Isolates}

The fungus was subcultured on PDA media and kept at $25 \pm 2{ }^{\circ} \mathrm{C}$ for 15 days. Subsequent, subculturing of isolates was done at an interval of 20 days. Such isolates were stored in a refrigerator at $4^{\circ} \mathrm{C}$. The cultures were revived monthly.

\subsection{Pathogenicity Test}

Pathogenicity test of MoT isolates was done in sterilized pot soil. Soils were collected from the field of Sher-e-Bangla agricultural university and sterilized at $121^{\circ} \mathrm{C}$ for $15 \mathrm{~min}$. at 15 PSI. The pots were filled up with sterilized soil. Disinfected viable seeds of the variety BARI GOM 26 were sown in sterilized soil in pots with 10 seeds per pot. At three leaf stage only two plants were kept in the pot by uprooting all seedlings. At the heading stage, panicles were inoculated with spore suspension adjusted to $1 \times 10^{6}$ spores $/ \mathrm{ml}$ with the help of hand sprayer. Control plants were inoculated with sterile distilled water. The inoculated plants were covered with polyethylene bags to keep $100 \%$ relative humidity and then kept in a humid chamber for 48 hours at $25 \pm 2^{\circ} \mathrm{C}$ ). Periodic monitoring was performed for the development of symptoms on the panicle 7 days after inoculation. A re-isolation was made and the identity of the fungus was confirmed according to the original description (Figure 2).

\subsection{Variation among the MoT Isolates}

\subsubsection{Morphological and Cultural Variation of MoT Isolates}

Cultural characters namely rate of growth, type of margin and colony color were recorded on three different solid media viz. Potato dextrose agar (PDA), Potato sucrose agar (PSA) and Oat meal agar (OMA) at 4 DAI (days after inoculation). Spore morphology was recorded after one month of inoculation.

\subsubsection{Preparation of Culture Media}

The composition and procedures for preparation of the media used in this experiment were followed by standard methods [20] [21]. The chemical composition of each medium is as follows. The ingredients for preparing different media are given in Table 1.

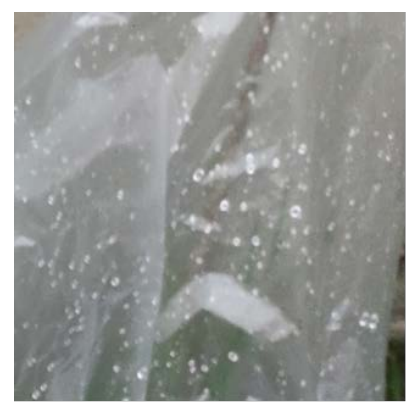

(a)

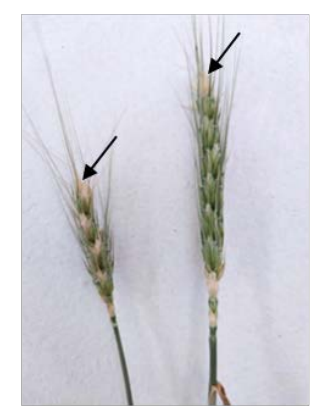

(b)

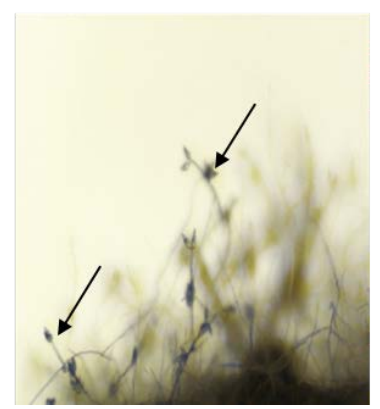

(c)

Figure 2. Artificially inoculated plant showing typical bleached panicle symptom; (a) Inoculated panicle covered with moistened poly bag, (b) Bleached panicle and (c) Pyriform conidia on inoculated rachis under stereomicroscope $(\times 40)$. 
Table 1. Ingredients used for preparation of different culture media for MoT isolates.

\begin{tabular}{cccc}
\hline Ingredients & $\begin{array}{c}\text { Potato Dextrose } \\
\text { Agar (PDA) }\end{array}$ & $\begin{array}{c}\text { Potato sucrose agar } \\
\text { (PSA) }\end{array}$ & $\begin{array}{c}\text { Oat meal agar } \\
\text { (OMA) }\end{array}$ \\
\hline Potato & $200 \mathrm{~g}$ & $200 \mathrm{~g}$ & - \\
Dextrose & $20 \mathrm{~g}$ & - & - \\
Agar & $20 \mathrm{~g}$ & $20 \mathrm{~g}$ & $20 \mathrm{~g}$ \\
Sucrose & - & $20 \mathrm{~g}$ & - \\
Oat meal & - & - & $37.0 \mathrm{~g}$ \\
Distilled water & $1000 \mathrm{ml}$ & $1000 \mathrm{ml}$ & $1000 \mathrm{ml}$ \\
\hline
\end{tabular}

\subsubsection{Procedure of Different Culture Media Preparation}

First, potatoes were peeled off and cut into small pieces. Then they were boiled and extract was filtered through the muslin cloth. The dextrose and agar were dissolved in the solution. Later sterilized the solution at $121^{\circ} \mathrm{C}$ at 15 PSI for 15 minutes. Same procedure was followed in case of Potato sucrose agar media. For Oat meal agar preparation, Oat meal and agar were added into $1000 \mathrm{ml}$ water in a conical flask. The volume was increased up to $1000 \mathrm{ml}$. Oat meal and agar were melted by heat and sterilized at $121^{\circ} \mathrm{C}$ at 15 PSI for 15 minutes.

\subsection{Experimental Design}

A total 15 isolates were grown and characterized on PDA, PSA and OMA where petri plates were randomized in three replications. The experimental design was Completely Randomized Design (CRD).

\subsection{Statistical Analysis}

Analyses of variances (ANOVA) for the data of different parameters were performed using Statistical Tool for Agricultural Research (STAR) software. The growth parameters of the isolates on different culture media were compared by least significant difference (LSD) with $5 \%$ level of probability.

\section{Result}

The results of the investigation on variability of wheat blast pathogen Magnaporthe oryzae triticum isolates are presented here under.

\subsection{Cultural and Morphological Variability among Magnaporthe oryzae triticum (MoT) Isolates}

Study on cultural characteristics of isolates of MoT was carried out on different culture media. Three solid media with fifteen isolates were used viz., Potato dextrose agar, Oat meal agar and Potato sucrose agar media. The different parameters considered for assessing the variability among the isolates were viz., colony diameter, colony color, colony margin, surface elevation of the pathogen. 


\subsection{Mean Mycelia Growth Rate and Growth Characteristics of 15 Isolates on Three Solid Media}

\subsubsection{Potato Dextrose Agar Media}

Colonies were ashy white to ash color sometime white color. Some isolates viz. MEMoT15, CHMoT11, CHMoT12, CHMoT13 having velvety surface (Figure 3). The remaining isolates have cottony surface. MEMoT13, MEMoT14, MEMoT16, MUMoT13, MUMoT14, MUMoT16, CHMoT11 have good growth of mycelia. MEMoT17, MEMoT18, MUMoT15 have medium growth and MUMoT17, CHMoT12, CHMoT13, CHMoT14 have poor mycelial growth. Almost all isolates produced pyriform, hyaline to pale olive conidia. Highest mycelial growth rate (11.75 mm per day) was observed in MUMoT16 at 4DAI (Days After Inoculation). Minimum mycelial growth rate $(6.50 \mathrm{~mm}$ per day) was recorded in $\mathrm{CH}$ MoT14 isolate at $4 \mathrm{DAI}$ (Table 2).

\subsubsection{Potato Sucrose Agar Media}

Most of the isolates viz. MEMoT14, MEMoT15, MEMoT18, MUMoT15, MUMoT16, CHMoT11, CHMoT12 showed ashy white colony. MEMoT13, MEMoT17, MEMoT13, MEMoT14 showed whitish, cottony surface colony. Rough

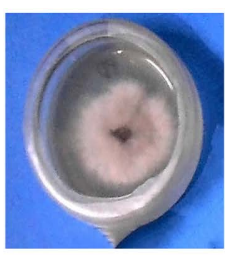

MEMoT13

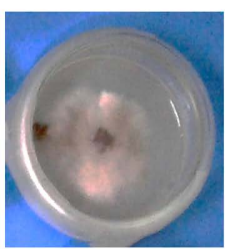

MEMoT17

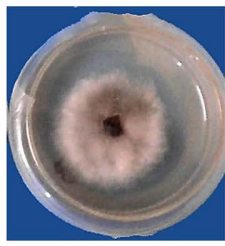

MUMoT15

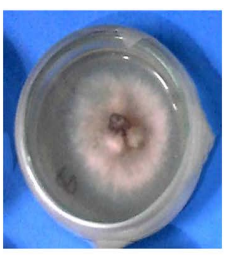

MEMoT14

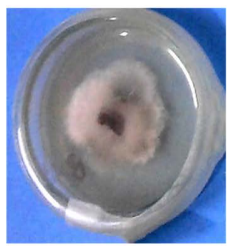

MEMoT18

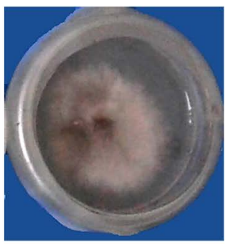

MUMoT16

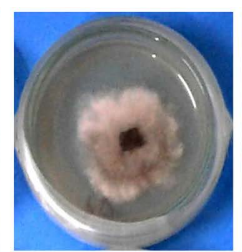

MEMoT15

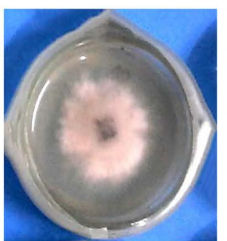

MUMoT13

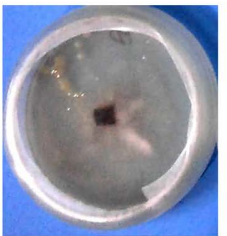

MUMoT17

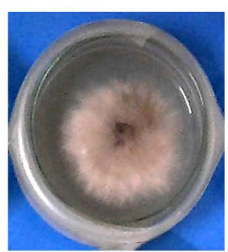

MEMoT16

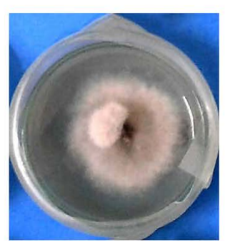

MUMoT14

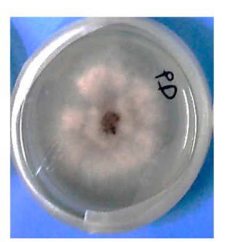

CHMoT11

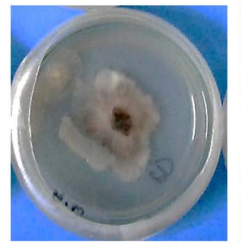

CHMoT12

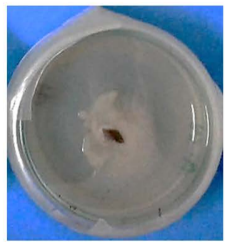

CHMoT13

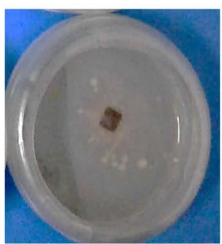

CHMoT14

Figure 3. Radial mycelial growth of 15 isolates of Magnaporthe oryzae triticum on PDA media at 4 DAI (days after inoculation). 
Table 2. Radial mycelial growth rate and Colony characters of 15 isolates of Magnaporthe oryzae triticum (MoT) on Potato dextrose agar media.

\begin{tabular}{|c|c|c|c|c|}
\hline $\begin{array}{l}\text { MoT } \\
\text { isolates }\end{array}$ & $\begin{array}{l}\text { Mycelial growth } \\
\text { rate at } 4 \text { DAI } \\
(\mathrm{mm} / \text { day })\end{array}$ & $\begin{array}{l}\text { Growth } \\
\text { pattern }\end{array}$ & Colony character & Conidial character \\
\hline MEMoT13 & $10.33 \mathrm{~cd}$ & Regular & $\begin{array}{l}\text { Whitish Ash, Smooth margin, } \\
\text { Good growth, Cottony }\end{array}$ & Pyriform, hyaline to pale olive \\
\hline MEMoT14 & $10.75 \mathrm{bc}$ & Regular & $\begin{array}{l}\text { Ashy white, Smooth margin, } \\
\text { Good growth, Cottony }\end{array}$ & Pyriform, hyaline to pale olive \\
\hline MEMoT15 & $10.25 \mathrm{~cd}$ & Regular & $\begin{array}{l}\text { Ashy White, rough margin, } \\
\text { Medium growth, Velvety }\end{array}$ & Pyriform, hyaline to pale olive \\
\hline MEMoT16 & $10.33 \mathrm{~cd}$ & Regular & $\begin{array}{l}\text { Whitish, Smooth margin, } \\
\text { Good growth, Cottony }\end{array}$ & Pyriform, hyaline to pale olive \\
\hline MEMoT17 & $11.25 \mathrm{ab}$ & Regular & $\begin{array}{l}\text { Whitish Ash, rough margin, } \\
\text { Medium growth, Cottony }\end{array}$ & Pyriform, hyaline to pale olive \\
\hline MEMoT18 & $10 \mathrm{~d}$ & Regular & $\begin{array}{l}\text { Ashy White, rough margin, } \\
\text { Medium growth, Cottony }\end{array}$ & Pyriform, hyaline to pale olive \\
\hline MUMoT13 & $10.08 \mathrm{~d}$ & Regular & $\begin{array}{l}\text { Whitish, Smooth margin, } \\
\text { Good growth, Cottony }\end{array}$ & Pyriform, hyaline to pale olive \\
\hline MUMoT14 & 8 ef & Regular & $\begin{array}{l}\text { Whitish, Smooth margin, } \\
\text { Good growth, Cottony }\end{array}$ & Pyriform, hyaline to pale olive \\
\hline MUMoT15 & $10.50 \mathrm{~cd}$ & Regular & $\begin{array}{l}\text { Ashy White, Smooth margin, } \\
\text { Medium growth, Cottony }\end{array}$ & Pyriform, hyaline to pale olive \\
\hline MUMoT16 & $11.75 \mathrm{a}$ & Regular & $\begin{array}{l}\text { Ashy White, rough margin, } \\
\text { Good growth, Cottony }\end{array}$ & Pyriform, hyaline to pale olive \\
\hline MUMoT17 & $8.25 \mathrm{e}$ & Regular & $\begin{array}{l}\text { Ash color, Rough margin, } \\
\text { Poor growth, Cottony }\end{array}$ & Pyriform, hyaline to pale olive \\
\hline CHMoT11 & $10.50 \mathrm{~cd}$ & Regular & $\begin{array}{l}\text { Ashy white, Smooth margin, } \\
\text { Good growth, Velvety }\end{array}$ & Pyriform, hyaline to pale olive \\
\hline CHMoT12 & $7.50 \mathrm{fg}$ & Regular & $\begin{array}{l}\text { Ashy white, rough margin, } \\
\text { Poor growth, Velvety }\end{array}$ & Pyriform, hyaline to pale olive \\
\hline CHMoT13 & $7.42 \mathrm{~g}$ & Regular & $\begin{array}{l}\text { Ashy color, Rough margin, } \\
\text { Very poor growth, Velvety }\end{array}$ & Pyriform, hyaline to pale olive \\
\hline CHMoT14 & $6.50 \mathrm{~h}$ & Regular & $\begin{array}{l}\text { Ashy color, Rough margin, } \\
\text { Very poor growth, Velvety }\end{array}$ & Pyriform, hyaline to pale olive \\
\hline LSD $(0.05)$ & 0.5729 & & & \\
\hline
\end{tabular}

margin was observed in isolates MEMoT15, MEMoT17, MEMoT18, MUMoT16, MUMoT17, CHMoT12, CHMoT13 and CHMoT14 (Figure 4). Other isolates showed smooth margin colony. Highest mycelial growth rate $(11.50 \mathrm{~mm}$ per day) was observed in isolate MEMoT18 at 4 DAI. Lowest mycelial growth rate was seen in MEMoT15 (5.58 mm per day) at 4 DAI. Rest of the isolates showed medium mycelial growth rate (Table 3 ). 
Table 3. Radial mycelial growth rate and Colony characters of 15 isolates of Magnaporthe oryzae triticum (MoT) on potato sucrose agar media.

\begin{tabular}{|c|c|c|c|c|}
\hline $\begin{array}{c}\text { MoT } \\
\text { isolates }\end{array}$ & $\begin{array}{l}\text { Mycelial growth rate } \\
\text { at } 4 \mathrm{DAI}(\mathrm{mm} / \text { day })\end{array}$ & $\begin{array}{l}\text { Growth } \\
\text { pattern }\end{array}$ & Colony character & Conidial character \\
\hline MEMoT13 & $10.83 \mathrm{bcd}$ & Regular & $\begin{array}{l}\text { Whitish Ash, Smooth margin, } \\
\text { Good growth, Cottony }\end{array}$ & Pyriform, hyaline to pale olive \\
\hline MEMoT14 & $11.08 \mathrm{ab}$ & Regular & $\begin{array}{l}\text { Ashy White, Smooth margin, } \\
\text { Good growth, Cottony }\end{array}$ & Pyriform, hyaline to pale olive \\
\hline MEMoT15 & $7.50 \mathrm{e}$ & Regular & $\begin{array}{l}\text { Ashy White, rough margin, } \\
\text { Medium growth, Velvety }\end{array}$ & Pyriform, hyaline to pale olive \\
\hline MEMoT16 & $11 \mathrm{abc}$ & Regular & $\begin{array}{l}\text { Whitish, Smooth margin, } \\
\text { Good growth, Cottony }\end{array}$ & Pyriform, hyaline to pale olive \\
\hline MEMoT17 & $10.25 \mathrm{~d}$ & Regular & $\begin{array}{l}\text { Whitish Ash, rough margin, } \\
\text { Medium growth, Cottony }\end{array}$ & Pyriform, hyaline to pale olive \\
\hline MEMoT18 & $11.50 \mathrm{a}$ & Regular & $\begin{array}{l}\text { Ashy White, rough margin, } \\
\text { Medium growth, Cottony }\end{array}$ & Pyriform, hyaline to pale olive \\
\hline MUMoT13 & $10.25 \mathrm{~d}$ & Regular & $\begin{array}{l}\text { Whitish, Smooth margin, } \\
\text { Good growth, Cottony }\end{array}$ & Pyriform, hyaline to pale olive \\
\hline MUMoT14 & $10.50 \mathrm{bcd}$ & Regular & $\begin{array}{l}\text { Whitish, Smooth margin, } \\
\text { Good growth, Cottony }\end{array}$ & Pyriform, hyaline to pale olive \\
\hline MUMoT15 & $10.42 \mathrm{~cd}$ & Regular & $\begin{array}{l}\text { Ashy White, Smooth margin, } \\
\text { Medium growth, Cottony }\end{array}$ & Pyriform, hyaline to pale olive \\
\hline MUMoT16 & $10.75 \mathrm{bcd}$ & Irregular & $\begin{array}{l}\text { Ashy White, rough margin, } \\
\text { Good growth, Cottony }\end{array}$ & Pyriform, hyaline to pale olive \\
\hline MUMoT17 & $6.58 \mathrm{f}$ & Irregular & $\begin{array}{l}\text { Ash color, Rough margin, } \\
\text { Poor growth, Cottony }\end{array}$ & Pyriform, hyaline to pale olive \\
\hline CHMoT11 & $10.25 \mathrm{~d}$ & Regular & $\begin{array}{l}\text { Ashy white, Smooth margin, } \\
\text { Good growth, Velvety }\end{array}$ & Pyriform, hyaline to pale olive \\
\hline CHMoT12 & $6.83 \mathrm{f}$ & Irregular & $\begin{array}{l}\text { Ashy white, rough margin, } \\
\text { Poor growth, Velvety }\end{array}$ & Pyriform, hyaline to pale olive \\
\hline CHMoT13 & $6.83 \mathrm{f}$ & Regular & $\begin{array}{l}\text { Ashy color, Rough margin, } \\
\text { Very poor growth, Velvety }\end{array}$ & Pyriform, hyaline to pale olive \\
\hline CHMoT14 & $5.58 \mathrm{~g}$ & Regular & $\begin{array}{l}\text { Ashy color, Rough margin, } \\
\text { Very poor growth, Velvety }\end{array}$ & Pyriform, hyaline to pale olive \\
\hline $\operatorname{LSD}(0.05)$ & 0.6664 & & & \\
\hline
\end{tabular}

\subsubsection{Oat Meal Agar}

Whitish to grey color colony, not raised, smooth margin of the colony and medium growth of the mycelium was found in almost all isolates except MEMoT14 having rough margin (Figure 5). All isolates show conidia which were hyaline to pale olive color with pyriform shape. Highest mycelial growth rate was recorded (11.91 mm per day) in isolate MUMoT13 at 4 DAI. Low radial mycelial growth rate (7.92 $\mathrm{mm}$ per day) was observed in MUMoT17 isolate at 4 DAI. Except CHMoT12, CHMoT13 and CHMoT14, rest of the isolates showed sufficient 


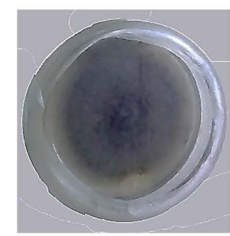

MEMoT13

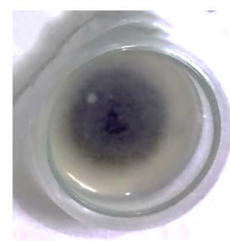

MEMoT17

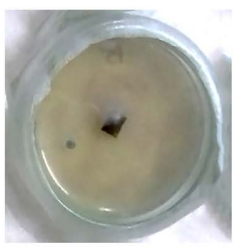

MUMoT15

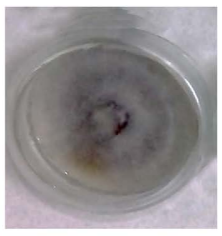

MEMoT14

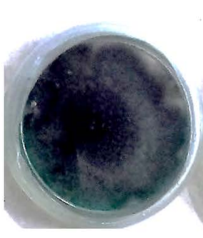

MEMoT18

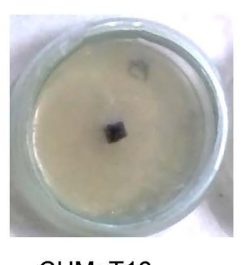

CHMoT16

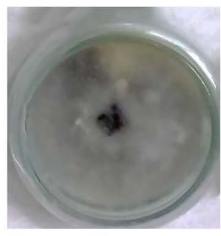

MEMoT15

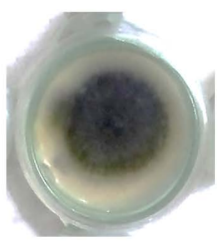

MUMoT13

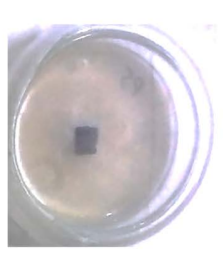

MUMoT17

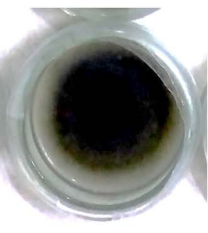

MEMoT16

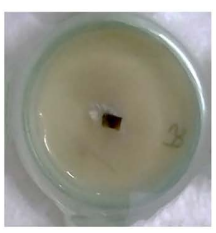

MUMoT14

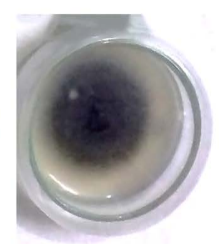

CHMOT 11

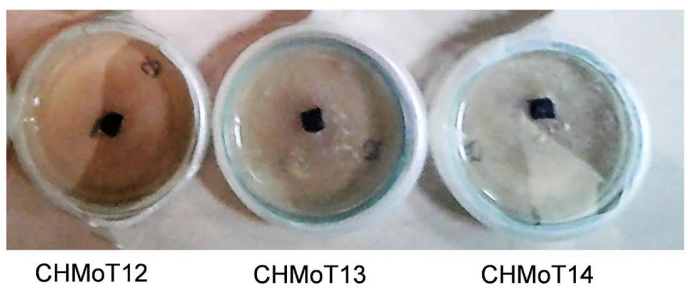

Figure 4. Radial mycelial growth of 15 isolates of Magnaporthe oryzae triticum on PSA media at 4 DAI (days after inoculation).

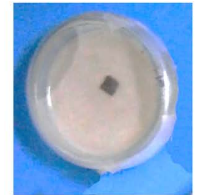

MEMoT13

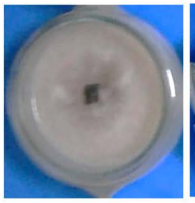

MEMoT18

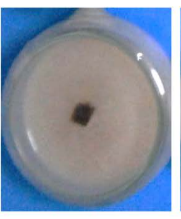

MUMoT17

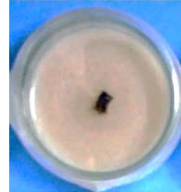

MEMoT14

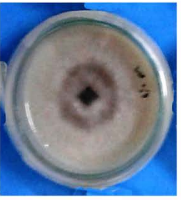

MUMoT13

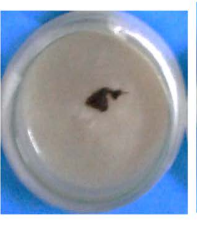

CHMoT11

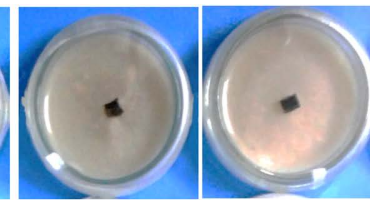

MEMoT15

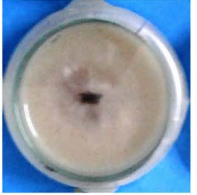

MUMoT14

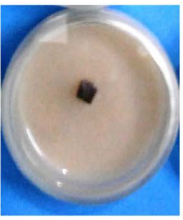

CHMoT12
MEMoT16

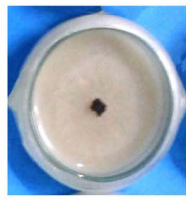

MUMoT15

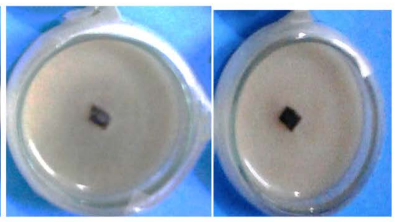

CHMoT13

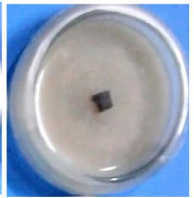

MEMoT17

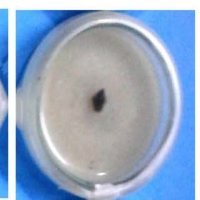

MUMoT16

CHMoT14

Figure 5. Radial mycelial growth of 15 isolates of Magnaporthe oryzae triticum on OMA at 4 DAI (days after inoculation). 
radial mycelial growth rate at $4 \mathrm{DAI}$ (Table 4$)$.

\section{Discussions}

Wheat is one of the most important cereal crops and the second most important grain crop after rice in our country [22]. Wheat blast has emerged as a new threat to wheat production in Bangladesh. Although the disease appeared for the first time in 2016 causing much destruction, it continued damaging wheat in

Table 4. Radial mycelial growth rate and Colony characters of 15 isolates Magnaporthe oryzae triticum (MoT) on Oat Meal Agar media.

\begin{tabular}{|c|c|c|c|c|}
\hline $\begin{array}{l}\text { MoT } \\
\text { isolates }\end{array}$ & $\begin{array}{l}\text { Mycelial growth rate } \\
\text { at } 4 \mathrm{DAI}(\mathrm{mm} / \text { day })\end{array}$ & $\begin{array}{l}\text { Growth } \\
\text { pattern }\end{array}$ & Colony character & Conidial character \\
\hline MEMoT13 & $10.63 \mathrm{c}$ & Regular & $\begin{array}{l}\text { Whitish, Smooth margin, } \\
\text { Not raised, Medium growth }\end{array}$ & Pyriform, hyaline to pale olive \\
\hline MEMoT14 & $10.75 \mathrm{bc}$ & Regular & $\begin{array}{l}\text { Gray, Smooth margin, } \\
\text { Not raised, Medium growth }\end{array}$ & Pyriform, hyaline to pale olive \\
\hline MEMoT15 & $10.33 \mathrm{c}$ & Regular & $\begin{array}{l}\text { Whitish, Smooth margin, } \\
\text { Not raised, Medium growth }\end{array}$ & Pyriform, hyaline to pale olive \\
\hline MEMoT16 & $10.38 \mathrm{c}$ & Regular & $\begin{array}{l}\text { Whitish, Smooth margin, } \\
\text { Not raised, Medium growth }\end{array}$ & Pyriform, hyaline to pale olive \\
\hline MEMoT17 & $11.25 \mathrm{~b}$ & Regular & $\begin{array}{l}\text { Whitish, Smooth margin, } \\
\text { Not raised, Medium growth }\end{array}$ & Pyriform, hyaline to pale olive \\
\hline MEMoT18 & $10.5 \mathrm{c}$ & Regular & $\begin{array}{l}\text { Whitish, Smooth margin, } \\
\text { Not raised, Medium growth }\end{array}$ & Pyriform, hyaline to pale olive \\
\hline MUMoT13 & $11.91 \mathrm{a}$ & Regular & $\begin{array}{l}\text { Whitish, Smooth margin, } \\
\text { Not raised, Medium growth }\end{array}$ & Pyriform, hyaline to pale olive \\
\hline MUMoT14 & $11.63 \mathrm{ab}$ & Regular & $\begin{array}{l}\text { Grayish White,rough margin, } \\
\text { Not raised, Medium growth }\end{array}$ & Pyriform, hyaline to pale olive \\
\hline MUMoT15 & $11.33 \mathrm{ab}$ & Regular & $\begin{array}{l}\text { Grayish Centre with whitish, Smooth } \\
\text { margin, Not raised, Medium growth }\end{array}$ & Pyriform, hyaline to pale olive \\
\hline MUMoT16 & $11.42 \mathrm{ab}$ & Regular & $\begin{array}{c}\text { Gray, Smooth margin, Not raised, } \\
\text { Medium growth }\end{array}$ & Pyriform, hyaline to pale olive \\
\hline MUMoT17 & $7.92 \mathrm{e}$ & Regular & $\begin{array}{l}\text { Whitish, Smooth margin, Not raised, } \\
\text { Medium growth }\end{array}$ & Pyriform, hyaline to pale olive \\
\hline CHMoT11 & $10.75 \mathrm{bc}$ & Regular & $\begin{array}{l}\text { Whitish, Smooth margin, Not raised, } \\
\text { Medium growth }\end{array}$ & Pyriform, hyaline to pale olive \\
\hline CHMoT12 & $9.00 \mathrm{~d}$ & Regular & $\begin{array}{l}\text { Whitish, Smooth margin, Not raised, } \\
\text { Medium growth }\end{array}$ & Pyriform, hyaline to pale olive \\
\hline CHMoT13 & $8.08 \mathrm{e}$ & Regular & $\begin{array}{l}\text { Whitish, Smooth margin, Not raised, } \\
\text { Medium growth }\end{array}$ & Pyriform, hyaline to pale olive \\
\hline CHMoT14 & $8.42 \mathrm{de}$ & Regular & $\begin{array}{l}\text { Whitish, Smooth margin, Not raised, } \\
\text { Medium growth }\end{array}$ & Pyriform, hyaline to pale olive \\
\hline LSD (0.05) & $100.5848 .63 c$ & & & \\
\hline
\end{tabular}


subsequent years but in a smaller scale [17]. As the MoT isolates can survive in seeds and crop residues and disease severity is highly dependent on prevailing conducive weather, it is likely that the disease can appear in the wheat fields in the next year without formulating an appropriate management strategy in the current year. To minimize the loss from the disease, it is essential to generate basic information of the pathogen. Our study described the cultural and morphological features of MoT isolates collected from blast infected fields in two south western districts namely Meherpur, Chuadanga in Bangladesh. Cultural and morphological characteristics of 15 MoT isolates grown on PDA, PSA and OMA showed variation among different isolates in respect to mycelial growth rate, growth pattern, colony color, colony margin, colony texture, compactness, arial hyphae, conidial characteristics etc. On PDA medium, highest mycelial growth rate was found in MUMoT16 (11.75 mm) which was collected from mujibnagar upazila and lowest mycelial growth rate was recorded in CHMoT14 (6.50 mm) collected from Chuadanga sadar upazila. Whitish to ashy white colour colony was observed in most of the isolates. The isolates also showed cottony to velvety surface, smooth or rough margin and good to medium growth. On PSA medium, highest mycelial growth rate $(11.50 \mathrm{~mm}$ per day) was observed in isolate MEMoT18 at 4 DAI collected from Meherpur sadar upazila. Lowest mycelial growth rate was observed in MEMoT15 isolate (5.58 $\mathrm{mm}$ per day) at 4 DAI. In this medium, the colony also showed ashy white to whitish colour, cottony surface, smooth or rough margin. On OMA medium, highest mycelial growth rate was recorded (11.91 mm per day) in isolate MUMoT13 at 4 DAI. Low radial mycelial growth rate (7.92 mm per day) was observed in MUMoT17 isolate at 4 DAI. The colony of most of the isolates was not raised in OMA. Most of the isolates showed ashy white to whitish and grayish color colony. The findings of the present study are supported by previous report [23]. They found that the morphology of MoT isolates was whitish to grey color. Some isolates showed smooth margin, some showed rough margin. In another study Tembo et al. (2020) [24] also showed that the colony of MoT isolates had rough or irregular margin and moderate grey appearance. However, no variation was found in case of growth pattern. All isolates showed regular growth pattern in all media. These results were almost similar to Meena (2005) [25]. Almost all isolates showed same conidial character in three growth media. Conidia are Pyriform, hyaline to pale olive which is supported by previous studies [24] [25] [26]. In this study it was also found that highest mycelial growth was observed on OMA medium followed by PDA and PSA media. Similar results were also reported by Asfaha et al. (2015) [27] that the OMA was suitable for growth of Pyricularia oryzae. Similarly, Kulkarni (1973) [28] reported that among the solid and liquid media, OMA was found to be good for the $P$. oryzae isolates. But this result disagreed with Castruagudin et al. (2016) [18]. They showed maximum mycelial growth was recorded on PDA. But they also observed hyaline to pale gray, pyriform asexual conidia. This result is almost similar to our study. 


\section{Conclusion}

In this study, $15 \mathrm{MoT}$ isolates were identified and morphologically characterized on three different growth media such as PDA, PSA and OMA. From this study it had been found that mycelial growth rate differed significantly among isolates and among growth media used. Different isolates showed different colony characteristics on different media. Mycelial growth rate and colony differences were also observed among the isolates on same media. This may be due to different strains or isolates, pathogenic variation of MoT, different geographic origin and different carbon sources and nutrient content in different media. In this study it was found that highest mycelial growth of MoT isolates was observed on OMA.

\section{Acknowledgements}

We thank anonymous reviewers for their kind review of the manuscript. This research was financially supported by Sher-e-Bangla Agricultural University Research System (SAURES), Project ID: SAU/SAURES/2019/1847/(35).

\section{Competing Interests}

Authors have declared that no competing interests exist.

\section{Authors' Contributions}

This work was carried out in collaboration among all authors. Author MLA conducted the research work. Author FMA designed and supervised the research work, conducted pathogenicity study and edited the manuscript. Author MKR, JFT and MA managed the literature searches. All authors read and approved the final manuscript.

\section{References}

[1] Curtis, B.C., Rajaram, S. and Gomez Macpherson, H. (2002) Bread Wheat Improvement and Production. FAO Plant Production and Protection Series No. 30. FAO, Rome.

[2] Dixon, J. (2007) The Economics of Wheat. Research Challenges to Field to Fork. In: Buck, H.T., Nisi, J.E. and Salomon, N., Eds., Wheat Production in Stressed Environments, Springer, Dordrecht, 9-22. https://doi.org/10.1007/1-4020-5497-1 2

[3] FAOSTAT (Food and Agriculture Organization of the United Nations Statistics Division) (2017) Production/Crop Rice Paddy.

[4] Kihoro, J., Njoroge, J.B., Murage, H., Ateka, E. and Makihara, D. (2013) Investigating the Impact of Rice Blast Disease on the Livelihood of the Local Farmers in Greater Mwea Region of Kenya. Springer Plus, 2, 308. https://doi.org/10.1186/2193-1801-2-308

[5] Couch, B. and Kohn, L. (2002) A Multilocus Gene Genealogy Concordant with Host Preference Indicates Segregation of a New Species, Magnaporthe oryzae, from $M$. grisea. Mycologia, 94, 683-693. https://doi.org/10.2307/3761719

[6] Kohli, M.M., Mehta, Y.R. and Guzman, E. (2011) Pyricularia Blast-A Threat to Wheat Cultivation. Czech Journal of Genetics and Plant Breeding, 47, S130. https://doi.org/10.17221/3267-CJGPB 
[7] Goulart, A.C.P. and Paiva, F.A. (1990) Transmission of Pyricularia oryzae by Wheat ( Triticum aestivum) Seeds. Fitopatologia Brasileira, 15, 359-362.

[8] Goulart, A.C.P. and Paiva, F.A. (1992) Incidencia da brusone (Pyricularia oryzae) emdiferentescultivares de trigo (Triticum aestivum) emcondicoes de campo. Fitopatologia Brasileira, 17, 321-325.

[9] Igarashi, S., Utimada, C.M. and Igarashi, L.C. (1986) Pyricularia em trigo. Ocorrencia de Pyricularia spp. no estado do Parana. Fitopatologia Brasileira, 11, 351-352.

[10] Malaker, P.K, Barma, N.C.D., Tiwari, T.P., Collis, W.J., Duveiller, E., Singh, P.K., Joshi, A.K., Singh, R.P., Braun, H.J., Peterson, G.L., Pedley, K.F., Farman, M.L., Valent, B., et al. (2016) First Report of Wheat Blast Caused by Magnaporthe oryzae Pathotype Triticum in Bangladesh. Plant Disease, 100, 2330.

https://doi.org/10.1094/PDIS-05-16-0666-PDN

[11] Lima, M.I.P.M. (2004) Informações gerais sobre giberela em trigo e em cevada. Embrapa Trigo. http://www.cnpt.embrapa.br/biblio/do/p do40.htm

[12] Prabhu, A.S., Filippi, M.C. and Castro, N. (1992) Pathogenic Variation among Isolates of Magnaporthe oryzae Affecting Rice, Wheat, and Grass in Brazil. Tropical Pest Management, 38, 367-371. https://doi.org/10.1080/09670879209371729

[13] Anjos, J.R.N.D., Silva, D.B.D. and Charchar, M.J.D. (1996) Occurrence of Blast Fungus (Pyricularia grisea) on Wheat and Rye in the Savanna Region of Central Brazil. Pesquera Agropecuaria Brasileira, 31, 79-82.

[14] Perello, A., Martinez, I. and Molina, M. (2015) First Report of Virulence and Effects Magnaporthe oryzae Isolates Causing Wheat Blast in Argentina. Plant Disease, 99, 1177. https://doi.org/10.1094/PDIS-11-14-1182-PDN

[15] Goulart, A.C.P., Sousa, P.G. and Urashima, A.S. (2007) Damages in Wheat Caused by Infection of Pyricularia grisea. Summa Phytopathologica, 133, 358-363. https://doi.org/10.1590/S0100-54052007000400007

[16] Callaway, E. (2016) Devastating Wheat Fungus Appears in Asia for First Time. Nature, 532, 421-422. https://doi.org/10.1038/532421a

[17] Islam, M.T., Kim, K.H. and Choi, J. (2019) Wheat Blast in Bangladesh: The Current Situation and Future Impacts. Plant Pathology, 35, 1-10.

https://doi.org/10.5423/PPJ.RW.08.2018.0168

[18] Castruagudin, V.L., Moreira, S.I., Pereira, D.A.S., Moreira, S.S., Brunner, P.C., Maciel, J.L.N., Crous, P.W., McDonald, B.A., Alves, E. and Ceresini, P.C. (2016) Pyricularia graminils tritici, a New Pyricularia Species Causing Wheat Blast. Persoonia, 37, 199-216. https://doi.org/10.3767/003158516X692149

[19] Aminuzzaman, F.M., Hossain, I. and Ahmed, F. (2010) Cultural Variation and Pathogenicity of Bipolaris sorokiniana on Wheat in Bangladesh. International Journal of Agriculture, Environment and Biotechnology, 3, 93-98.

[20] Dhingra, O.D. and Sinclair, J.B. (2019) Basic Plant Pathology Methods. Second Edition, CRC Press, Boca Raton, 132-163. https://doi.org/10.1201/9781315138138

[21] Tuite, J. (1969) Plant Pathological Methods: Fungi and Bacteria. Burgess Publishing Company, $239 \mathrm{p}$.

[22] Hossain, A., Jaime, A. and Silva, T. (2013) Wheat Production in Bangladesh: Its Future in the Light of Global Warming. AoB Plants, 5, 42. https://doi.org/10.1093/aobpla/pls042

[23] Islam, M.T., Croll, D., Gladieux, P., Soanes, D.M., Persoons, A., Bhattacharjee, P., Hossain, M.S., Gupta, D.R., Rahman, M.M., Mahboob, M.G., Cook, N., Salam, M.U., Surovy, M.Z., Sancho, V.B., Maciel, J.L.N., Nhani, A., Castroagudin, V.L., Reg- 
es, J.T.D., Ceresini, P. C., Ravel, S., Kellner, R., Fournier, E., Tharreau, D., Lebrun, M.H., Mcdonald, B.A., Stitt, T., Swan, D., Talbot, N.J., Saunders, D.G.O., Win, J. and Kamoun, S. (2016) Emergence of Wheat Blast in Bangladesh Was Caused by a South American Lineage of Magnaporthe oryzae. BMC Biology, 14, 11.

https://doi.org/10.1186/s12915-016-0309-7

[24] Tembo, B., Mulerga, R.M., Sichilima, S., M’siska, K.K., Mwale, M., Chikoti, P.C., et al. (2020) Detection and Characterization of Fungus (Magnaporthe oryzae Pathotype Triticum) Causing Wheat Blast Disease on Rain-Fed Grown Wheat (Triticum aestivum L.) in Zambia. PLoS ONE, 15, e0238724.

https://doi.org/10.1371/journal.pone.0238724

[25] Meena, B.S. (2005) Morphological and Molecular Variability of Rice Blast Pathogen Pyricularia grisea (Cooke) Sacc. M.Sc. Thesis, Dharwad University of Agricultural Sciences, Dharwad.

[26] Tanjina, A., Aminuzzaman, F.M., Islam, M.R., Joty, A.A., Laila, L. and Rayhanul, M.I. (2019) Survey on Wheat Blast and Morphological Variability of Magnaporthe oryzae triticum in Two South-Western Districts of Bangladesh. Bangladesh Journal of Plant Pathology, 35, 39-46.

[27] Asfaha, M.G., Selvaraj, T. and Woldeb, G. (2015) Assessment of Disease Intensity and Isolates Characterization of Blast Disease (Pyricularia oryzae CAV.) from South West of Ethiopia. Life Sciences, 3, 271-286.

[28] Kulkarni, S. (1973) Studies on the Blast Disease of Eleusine coracana (L.) Gaertn. (Finger Millet or Ragi) in Mysore State. M.Sc. (Agri) Thesis, U.A.S., Bangalore, 104. 